\title{
Role of Digitalisation and Technology in Dairy Supply Chain Management
}

\author{
K.S.Kanna ${ }^{1}$, Dr. R. Amudha ${ }^{2}$ \\ Research Scholar, Karunya School of Management, Karunya Institute of Technology and Sciences, Coimbatore ${ }^{1}$ \\ Associate Professor, Karunya School of Management, Karunya Institute of Technology and Sciences, Coimbatore ${ }^{2}$
}

\begin{abstract}
The Indian dairy business has witnessed major changes. The country's transformation from a milk shortage state in the 1950s to the world's largest milk producer is remarkable. With a compound Annual Growth Rate of 4.7 percent, milk production has increased significantly and contributes $22 \%$ to the world's milk production. The dairy industry continues to be one of the most important sources of income for 80 million rural people. India has been the world's largest producer of milk since the White Revolution in the 1970s, with annual production of 198.4 million MT (2019-20). Digitalisation will have a profound impact on the 'Milk Production' segment in the value chain. In India, dairy farming is unorganized, so technology penetration is relatively less; however, in the last five years, a few start-ups have mushroomed in this space. These firms aim to increase farmer productivity and reduce wastage. Supply chain of the Indian dairy industry is quite complex owing to its dependency on various factors such as ambient temperature, availability of cold chains and shorter shelf life. The fragmented Indian dairy industry further adds to the complexity. Digitalisation solutions such as the IoT and advanced analytics can help by sharing real-time data with different stakeholders, and detecting any deviations in the quality and quantity of milk during phases of transportation in the value chain. Thus, digitalization of the dairy sector could help the farmers and the industrialists for efficient management at each stage of processing.
\end{abstract}

\section{INTRODUCTION:}

Over the years, the Indian dairy business has witnessed major changes. The country's transformation from a milk shortage state in the 1950s to the world's largest milk producer is remarkable. With a compound Annual Growth Rate of 4.7 percent, milk production has increased significantly and contributes $22 \%$ to the world's milk production. Domestic demand for milk has absorbed the majority of the "white revolution-driven expansion" in milk output, leaving only a small and irregular excess for export. As a result, India's contribution to global dairy exports is less than $1 \%$.

From 198.7 million in 1951 to 302.3 million in 2019, India's total bovine population has grown by 52 percent [1]. However, the full productivity potential of the Indian milch herd has yet to be realised. Despite its time to focus on rising production expansion, the sector faces a number of obstacles along the value chain. The covid outbreak in 2020 has increased the focus on using technology and digitalisation to address supply chain concerns.

India's entire proportion of global milk production is predicted to rise to $26 \%$ by 2030 , up from current $22 \%$. The following factors outlines the outlook for the Indian dairy sector in 2030 to provide an overview of the industry's evolving situation.

\section{MILK PRODUCTION:}

The dairy industry continues to be one of the most important sources of income for 80 million rural people [2]. India has been the world's largest producer of milk since the White Revolution in the 1970s, with annual production of 198.4 million MT (2019-20).

In 2019-2020, India shipped 51,421.9 MT of dairy products worth INR 13.4 billion, accounting for less than $1 \%$ of global dairy exports [7] and India consumes the majority of its dairy products domestically. India also has the world's largest livestock population (535.8 million), with cattle and buffalo accounting for almost 56\%. Buffaloes generate the majority of the milk [8]. Large cattle populations, not the productivity, is responsible for India's high milk production. As a result, boosting milk yields through improved genetics, better animal health management, and increased feed supply is critical to India's future milk production potential.

The value of an individual dairy cow depends greatly on its projected milk yield. In developed countries with developed dairy industry infrastructures, facilities exist to record individual cow production and reproduction outcomes consistently and accurately. There are proven statistical methods to predict the future milk production of a dairy cow based on herd recording data. The method consists of several steps to evaluate lifetime milk production and individual cow somatic cell counts and to finally predict the average production for each day that the cow can yield throughout its life time. 
Digitalisation will have a profound impact on the 'Milk Production' segment in the value chain. In India, dairy farming is unorganized, so technology penetration is relatively less; however, in the last five years, a few start-ups have mushroomed in this space. These firms aim to increase farmer productivity and reduce wastage.

Cattle management is one of the key areas where digitalisation can have a significant impact. By leveraging the Internet of Things (IoT) and advanced analytic, farmers can track the feeding pattern of cattle and monitor their health. This is likely to improve cattle productivity and increase milk yield. However, cattle monitoring through AI-based solutions is still at a nascent stage in India and only a few companies are offering this solution.

Apart from cattle management, the other potential areas of dairy digitalisation are supply chain and farmer payments. Supply chain of the Indian dairy industry is quite complex owing to its dependency on various factors such as ambient temperature, availability of cold chains and shorter shelf life. The fragmented Indian dairy industry further adds to the complexity. Digitalisation solutions such as the IoT and advanced analytics can help by sharing real-time data with different stakeholders, and detecting any deviations in the quality and quantity of milk during phases of transportation in the value chain.

Another potential benefit of digitalising dairy supply chain is better decision-making. Real-time data and advanced analytic help automate activities such as order tracking, inventory management, payments tracking and sales growth and facilitate better understanding of customer purchase patterns.

Dairy co-operatives and privates are now focusing on introducing digital payments to farmers. Farmers will be able to benefit from financial inclusion as a result of digital payments, which will provide transparency and cost savings. Enabling direct digital payments to farmer bank accounts makes it easier to build and administer data-driven farmer beneficiary programmes. As a large chunk of India's dairy industry is controlled by small farmers, the process of digital payments has its own set of challenges as most small farmers do not have a bank account. However, dairy co-operatives such as the Gujarat Co-operative Milk Marketing Federation (GCMMF), famously known as 'Amul', are opening bank accounts for dairy farmers and instantly transferring payments to them.

Figure 1: Milk production (million MT), per Capita Availability (gm/day) in India and its Share in World Milk Production

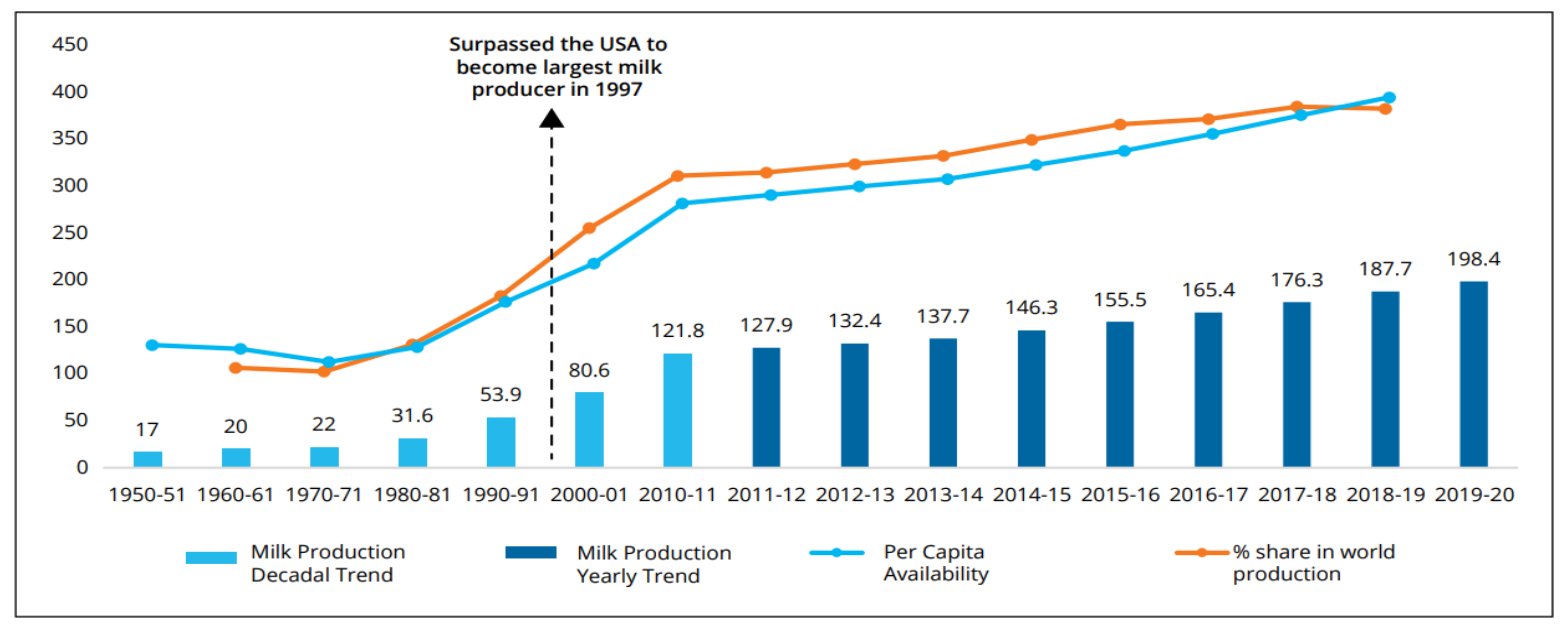

Source: NDDB, FAOSTAT, YES BANK Analysis

Figure 2: Milk Productivity of India vis-a-vis Other Regions 


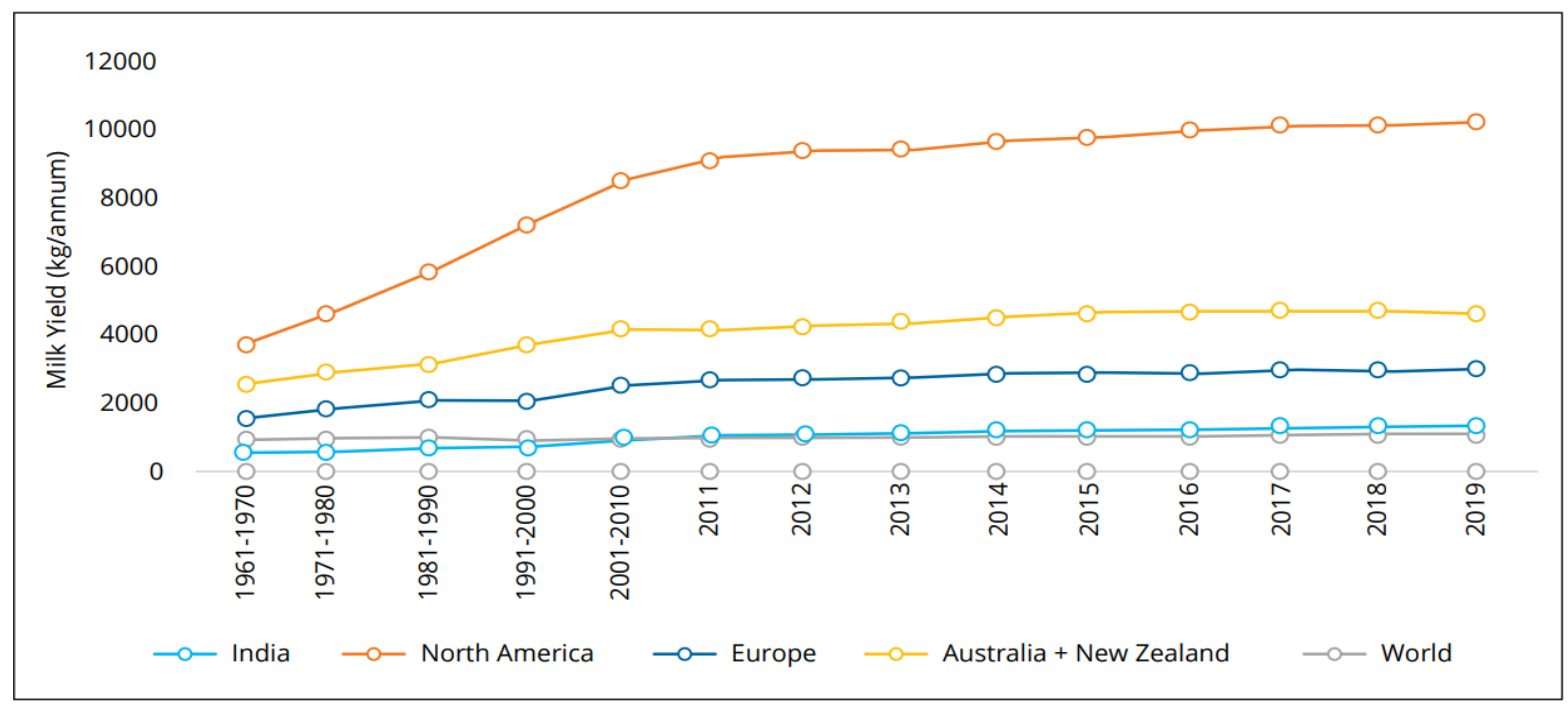

Source: FAOSTAT, YES BANK Analysis

Though India is topping in milk production in the World, the production can be further amplified with digitisation of the activities so that the milk producers need not spend 7 days $x 24$ hours in managing the dairy farms and at the same time improving their productivity.

\section{ANIMAL NUTRITION:}

The feed \& fodder for cattle has an impact on their health, nutritional content of milk and overall cost of milk production. Feed accounts for about 60-70 percent of the total cost of milk production in India. But, the dairy farms which are being managed on scientific lines are able to contain the feeding cost within $60 \%$ of the total price received for the milk sold.

It is pertinent to mention here that Dr Verghese Kurien realised the importance of feeding with adequate nutrients for cattle, established the first Cattle Feed Plant in dairy cooperative sector at Kanjiri near Anand. This pattern was replicated throughout the country under Operation Flood with an objective to contain the cost of milk production and improving the productivity and quality. NDDB had introduced Ration Balancing Programme two decades back and it supported the milk producers in the cooperative sector to regulate the economic production of milk.

Currently, there are many Applications available in the Android phones, floated by Veterinary Universities across the country, NIANP (ICAR), NDDB and a few companies involved in nutrition of bovines. Milk Producers have started using these Apps and are getting benefitted. This is a welcoming trend in the Indian Dairying and the industry will definitely be becoming more rational in the coming years.

\section{LIVESTOCK HEALTHCARE \& GENETICS:}

Increasing dairy production through high yielding breeds may not have the desired effect unless it is accompanied by improved illness diagnosis and health care management. Despite India's excellent veterinary infrastructure, access and awareness hamper the desired outcomes. Farmers are transiting from curative to preventative healthcare now-a-days. Accessibility will be driven in future by technology such as the Internet of Things (IoT) as well as mobile sensors.

A few Companies are offering cattle management solutions utilising AI and the IoT to monitor cattle breeding and send timely alerts to farmers. A wearable device for cattle has been developed by the companies with a mobile application which provides recommendations to optimise herd performance. According to some reports, by adopting digital solutions, milk yield can be increased by $20 \%$ and cattle health expenses can be reduced up to $50 \%$.

Digitalization has the potential to significantly improve farm management procedures. The animal wearable tag/belt is a comfortable, non-invasive IoT solution for detecting the commencement of the cow's heat cycle in a timely manner. These tags to determine the heat and health state of an individual cow or herd will drastically eliminate manual intervention and guesswork, resulting in enhanced farm productivity, animal health, and herd management. Farmers can 
receive timely signals via a smartphone app, allowing them to keep track of cattle breeding and arrange artificial insemination accordingly, assuring a high success rate. In India, however, cattle monitoring with AI-based technologies is still in its infancy.

\section{DAIRY PROCESSING:}

For the vegetarian population of India, dairy products constitute an essential source of protein. The Indian dairy sector is currently valued at around INR 7.5 trillion, with liquid milk accounting for 65 percent of the market. Consumers' increased concern on quality, safety, and sanitation forces the organised dairy industry to resort to automation.

Delivering consistent quality dairy products under the pressure to reduce costs can only be achieved through tighter control and higher level of automation. In dairy industry worldwide, compliance with ever-changing food safety and environmental standards, ageing assets, rising cost of energy, raw material and logistics, call for factory modernisation and optimisation. The trend is towards faster turnaround, closer integration of production scheduling with logistics and digitalisation of manufacturing operations.

Plant operations can also be managed remotely with minimal manual intervention thanks to digitalization-related technology breakthroughs. Manufacturers will be able to recognise shifting consumer trends and ensure that their operations will better support these changing trends by automatically updating their capabilities by combining production data with total value chain monitoring.

While liquid milk continues to dominate the market, demand for value-added dairy products is growing, particularly in metropolitan areas. In terms of value, VADPs such as ghee, paneer, butter, ice cream, and curd account for about $35 \%$, they fuel the industry's growth rates because of their high margin.

\section{EFFICIENT PRODUCTION PLANNING:}

By bringing together data collected at all levels of manufacture and giving analysis for better decision making, digital intervention can assist dairy processors in monitoring their performance. This results in higher output efficiencies and cheaper manufacturing costs. Companies can better track their inventory and how they might be deployed with more visibility and data.

\section{REMOTE MONITORING OF SUPPLY CHAIN:}

High-end technologies have the potential to change the dairy supply chain by providing timely access to essential insights for both milk producers and processors. Furthermore, quality and traceability solutions might turn India into a dairy export powerhouse, and data-driven dairy farming decisions could lead to the creation of a smart dairy supply chain.

New generation technology such as the Internet of Things (IoT) will improve checks on product parameters, Blockchain has the potential to boost transparency, or Radio-Frequency Identification (RFID)-enabled transportation and packaging are traceable can be utilised for real-time supply chain tracking and management by sharing real-time data with various stakeholders during transportation phases.

\section{BLOCK CHAIN TECHNOLOGY FOR TRACEABILITY:}

Blockchain is a technology that can enable individuals and institutions to make immediate network transactions without any mediator (when decentralised). Transactions conducted on the blockchain are entirely secure and stored as a record of what has occurred as a role of blockchain technology. Cryptographic encryption algorithms assure that no blockchain transaction document can be modified after a particular event takes place. Blockchain is a decentralised and shared ledger where blocks comprising a collection of transactions are joined together by a cryptographic hash.

Dairy traceability is used to trace the milk and milk products' journey via various routes - production to its final consumption. Unlike years ago, there has been a decline in the connection between dairy producers, processors/manufacturers, merchants, and buyers. Very little or no information reaches consumers.

Although the dairy supply chain members retain different data, they mostly lack communication and coordination. Such a lack of interaction amongst the farmers and consumers, accompanied by the dairy industry's globalisation, has raised a demand for a better traceability system for India's milk and milk products. 
In modern scientific literature, the usage of Blockchain technology and the IoT is viewed as the potential solution to enhance traceability in the agri-food supply chain arrangement. As the dairy goods in the market are becoming ever more diverse, the supply chain is getting complicated and vast, necessitating trustworthiness. Hence, a Dairy Supply chain blockchain appears as the only solution to the trust and quality dilemma.

The use of blockchain in the dairy industry guarantees to build confidence in the goods, which eventually raises the demand for the package. This covers the secure handling and storing of official records and digital authentication to uphold intellectual property rights and patent systems, introduce transparency throughout the supply chain, decrease food fraud, and heighten food safety.

\section{CONCLUSION :}

Our Indian country transformed from its great demand in the 1950's and today the same nation developed as the world's largest milk producer. But the current need for this sector is a technological intervention for further improvisation. Though digitalisation in India is in its nascent stage, it would help dairy farmers in areas like cattle feed and health management, farmers' payment and order tracking, sales growth and inventory and supply chain management.

The non-invasive IoT solution eliminates the manual intervention in dairy processing plant operation which reduces chances of hazardous contamination. Furthermore, quality and traceability solutions might turn India into a dairy export powerhouse, and data-driven dairy farming decisions could lead to the creation of a smart dairy supply chain.

New generation technology like Blockchain has the tremendous potential to boost transparency which also enables individuals and institutions to make immediate and secured transactions without any mediator. Both the IoT and Blockchain technology together enhanced the traceability in the agri-food supply chain management. Thus, digitalization of the dairy sector could help the farmers and the industrialists for efficient management at each stage of processing.

\section{REFERENCE}

1. Statistics, B. A. H. (2019). Department of Animal Husbandry and Dairying. Ministry of Fisheries, Animal Husbandry and Dairying, Government of India.

2. Statistics, G. B. A. H. (2013). Department of Animal Husbandry, Dairying and Fisheries, Ministry of Agriculture. Government of India, New Delhi.

3. Aayog, N. I. T. I. (2020). Demand and supply projections towards 2033. Crops, Livestock, Fisheries and agricultural inputs, Working Group Report.

4. Outlook, O. F. A. (2012). OECD/FAO.

5. Aayog, N. I. T. I. (2020). Demand and supply projections towards 2033. Crops, Livestock, Fisheries and agricultural inputs, Working Group Report.

6. Husbandry, B. A., \& Statistics, F. (2014). Department of animal husbandry, dairying and fisheries. Ministry of agriculture.

7. Agricultural \& Processed Food Products Export Development Authority (APEDA), Ministry of Commerce \& Industry, Govt. of India.

8. Basic Animal Husbandry Statistics - 2019. 